\title{
Studies on Bile Acids
}

\section{THE MICROQUANTITATIVE SEPARATION OF CELLULAR BILE ACIDS BY GAS-LIQUID CHROMATOGRAPHY}

\author{
By TATSUO OKISHIO, PADMANABHAN P. NAIR AND MAUREEN GORDON \\ Biochemistry Research Division, Department of Medicine, \\ Sinai Hospital of Baltimore Inc., Baltimore, Md. 21 215, U.S.A.
}

(Received 23 August 1966)

\begin{abstract}
1. A method is described for the quantitative isolation of bile acids from cellular material. Homogenates of rat liver are freeze-dried and extracted exhaustively with $95 \%(v / v)$ ethanol containing $0.1 \%(v / v)$ of aq. ammonia (sp.gr. 0.88 ) and purified by anion-exchange chromatography on Amberlyst A-26. 2. The extracted bile acid conjugates are subjected to either of two hydrolytic procedures, one involving chemical and the other enzymic agents. A unique feature in this study is the introduction of an enzyme, a clostridial peptide-bond hydrolase, for the rapid cleavage of bile acid conjugates, replacing the classical drastic chemical hydrolysis with strong alkali. 3. After hydrolysis, free bile acids are methylated and converted into their trifluoroacetates for final determination by gas-liquid chromatography on a triple component column, FS-1265-SE 30-NGS. 4. For the purpose of identification of peaks, bile acid methyl esters are converted into their trimethylsilyl ethers by allowing the methyl esters to react with a new and potent silyl donor, bis(trimethylsilyl)acetamide. 5. The technique affords us a means of studying the metabolism of bile acids at the cellular and subcellular levels in tissues.
\end{abstract}

Cholic acid and chenodeoxycholic acid are the principal end products of cholesterol metabolism and constitute the primary bile acids in most mammals, giving rise in turn to the secondary bile acids, almost all of which retain the dominant $5 \beta$ cholanic acid structure (Haslewood, 1964). Our present knowledge on the biogenesis and enterohepatic metabolism of these substituted cholanic acids has been limited to studies on bile, blood and intestinal contents (faeces) (Sjövall, 1964a) as the direct result of inadequate techniques for their isolation and determination from cellular material.

The present paper is an extension of previous work on gas-liquid chromatography of constituent bile acids from normal serum (Sandberg, Sjövall, Sjövall \& Turner, 1965) and deals with the determination of bile acids from tissue homogenates and subcellular fractions. Advances in the methodology of the bile acids are now reported, including the enzymic cleavage of naturally occurring bile acids with a peptide-bond hydrolase derived from a strain of Clostridium perfringens (A.T.C.C. 19574), isolated by Nair, Gordon, Gordon, Reback \& Mendeloff (1965). In contrast, drastic alkaline hydrolytic procedures are time-consuming and result in some degradative losses (Irwin, Johnston
\& Kopala, 1944; Levin, Irwin \& Johnston, 1961). Improvements have also been made in the final gas-liquid-chromatographic technique by using a highly reproducible triple component column (Okishio \& Nair, 1966a). Bile acid methyl esters are converted into the corresponding trimethylsilyl ethers by allowing them to react with a new and potent silyl donor, bis(trimethylsilyl)acetamide. Our techniques have been applied to a study of major substituted cholanic acids in subcellular fractions from rat liver (Okishio \& Nair, 1966b). A preliminary report of this work has appeared (Okishio \& Nair, 1965).

\section{EXPERIMENTAL}

Nomenclature of bile acids. Bile acids are referred to in this paper by the following trivial names: lithocholic acid, $3 \alpha$-hydroxy-5 $\beta$-cholanic acid; hyodeoxycholic acid, $3 \alpha, 6 \alpha$ dihydroxy-5 $\beta$-cholanic acid; chenodeoxycholic acid, $3 \alpha, 7 \alpha-$ dihydroxy-5 $\beta$-cholanic acid; deoxycholic acid, $3 \alpha, 12 \alpha$ dihydroxy-5 $\beta$-cholanic acid; cholic acid, $3 \alpha, 7 \alpha, 12 \alpha$-trihydroxy-5 $\beta$-cholanic acid.

Materials. Standard free bile acids (cholic acid, deoxycholic acid, chenodeoxycholic acid, lithocholic acid and hyodeoxycholic acid) were obtained from commercial sources (Nutritional Biochemicals Corp., Cleveland, Ohio, 


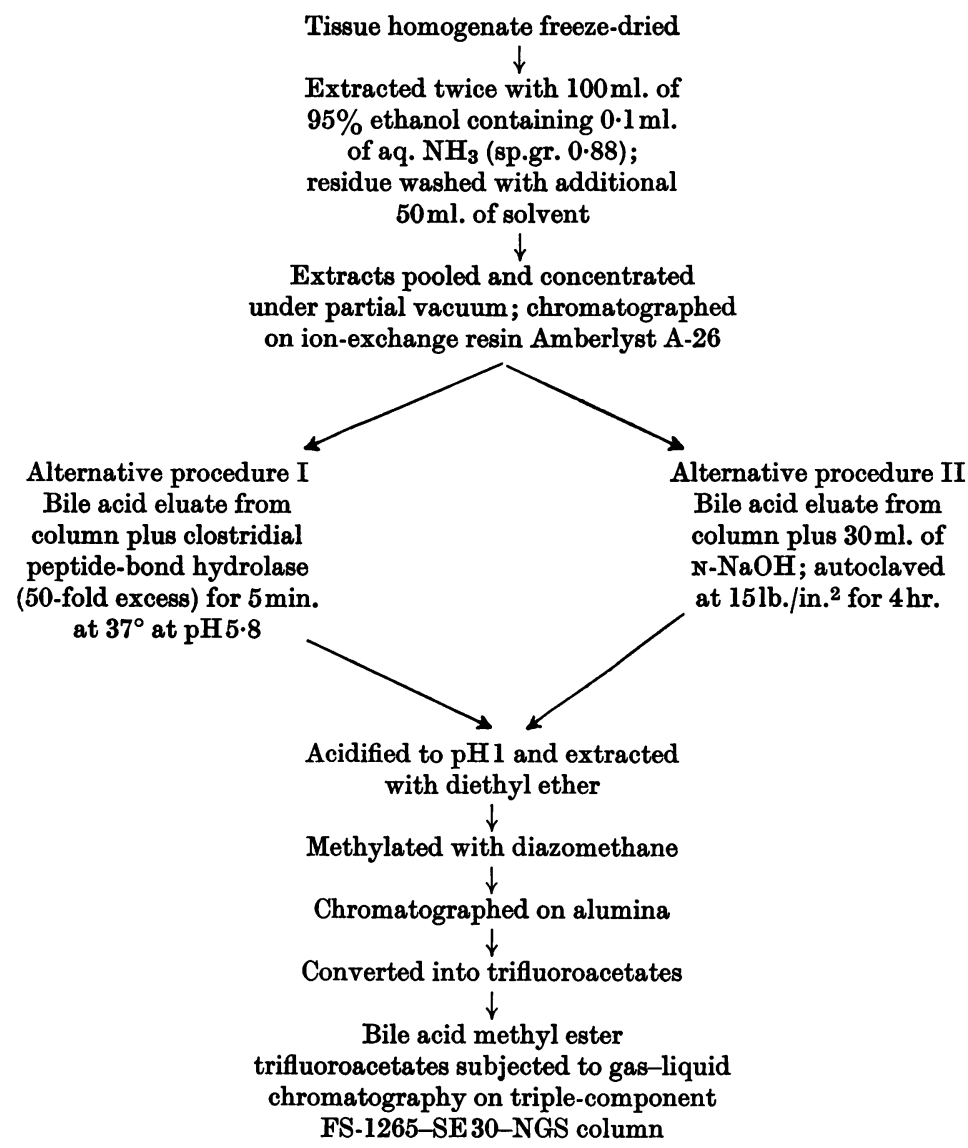

Scheme 1. Flow sheet indicating steps of isolation and quantitative separation of tissue bile acids.

U.S.A., and California Corp. for Biochemical Research, Los Angeles, Calif., U.S.A.). Taurocholic acid and glycocholic acid were prepared by the mixed anhydride method of Norman (1955).

Amberlyst A-26 (formerly XN-1006) anion-exchange resin (Rohm and Haas Co., Philadelphia, Pa., U.S.A.), neutral alumina, activity grade I (Bio-Rad Laboratories, Richmond, Calif., U.S.A.), and all solvents (Certified Reagents; Fisher Scientific Co., Pittsburgh, Pa., U.S.A.) were purified and stored as described by Sandberg et al. (1965).

Bis(trimethylsilyl)acetamide, a silyl donor, was prepared for us by Dr J. F. Klebe, Polymer Reactions Group, General Electric Co., Schenectady, N.Y., U.S.A.

An E.I.R. (Electronic Instruments for Research) analytical gas chromatograph (model AU-8) equipped with an argon ionization detector $\left(20 \mathrm{mc}\right.$ of ${ }^{90} \mathrm{Sr}$ ) was used. The following conditions were generally employed for gas-liquid chromatography: inlet temperature, $240^{\circ}$; column temperature, $210^{\circ}$; detector temperature, $230^{\circ}$; outlet flow rate, $75 \mathrm{ml} . / \mathrm{min}$. The electrometer gain was set at $1 \mathrm{~m} \mu \mathrm{A}$ to give a full-scale deflection on a $10 \mathrm{mv}$ recorder at a detector voltage of 1000 .
A triple-component column consisting of a mixture of FS-1265 (fluoroalkyl polysiloxane, QF-1; Dow Corning Corp., Midland, Mich., U.S.A.), NGS* and SE 30 (methyl polysiloxane; General Electric Co., Schenectady, N.Y., U.S.A.) phases was used for quantitative gas-liquid chromatography (Okishio \& Nair, 1966a) of the methyl ester trifluoroacetates. The shifts in relative retention times observed on conversion of free bile acid methyl esters into the corresponding trimethylsilyl ethers aided in identification of the peaks.

Preparation of derivatives. The bile acids were methylated with diazomethane, prepared as described by Schlenk \& Gellerman (1960). The extract containing bile acids was dissolved in $10.0 \mathrm{ml}$. of ether and $1.0 \mathrm{ml}$. of methanol. The solution was then allowed to react with excess of diazomethane (denoted by a persistent yellow colour) for $15 \mathrm{~min}$., at the end of which the solvent was removed under partial vacuum.

Bile acid methyl esters were converted into their trifluoroacetates as described by Sandberg et al. (1965). Trimethylsilyl ethers were prepared by the addition of

* Abbreviation: NGS, neopentyl glycol succinate. 
$0.2-0.3 \mathrm{ml}$. of bis(trimethylsilyl)acetamide to bile acid methyl esters and the reaction mixture was maintained at $55^{\circ}$ for $3 \mathrm{hr}$. The residue was dissolved in acetonitrile for gas-liquid chromatography.

Isolation procedure. Tissue homogenates of subcellular fractions were freeze-dried and then refluxed for $30 \mathrm{~min}$. with $100 \mathrm{ml}$. of $95 \%(v / v)$ ethanol containing $0 \cdot 1 \%(v / v)$ of aq. $\mathrm{NH}_{3}$ (sp.gr. 0.88). The residue was re-extracted with the same volume of fresh solvent and filtered. The material left on the filter paper was washed with $50 \mathrm{ml}$. of fresh extractant. The extracts were pooled and evaporated to dryness under reduced pressure.

Bile acids in the residue were dissolved in $3 \cdot 0-7 \cdot 0 \mathrm{ml}$. of $0 \cdot 1 \mathrm{~N}-\mathrm{NaOH}(\mathrm{pH} 11)$ and transferred to an Amberlyst A-26 anion-exchange resin column with the addition of $35 \mathrm{ml}$. of water. All subsequent steps in purification except enzymic hydrolysis and chromatography on alumina were performed as described by Sandberg et al. (1965) (Scheme 1).

Enzymic hydrolysis of bile acid conjugates. A strain of Clostridium perfringens that yielded an enzyme capable of cleaving the carbon-nitrogen bond of bile acid conjugates was isolated by Nair et al. (1965) from human urine, with trypticase-soya-blood agar (A.T.C.C. 19574). An alternative procedure for the cleavage of conjugated bile acids involved the use of a cell-free extract from this organism for the enzymic hydrolysis of the peptide bond. The enzyme was prepared as described by Nair et al. (1965). A sample of biological material (eluted from the Amberlyst column) containing approx. $100 \mu \mathrm{g}$. of total conjugated bile acids was dried under reduced pressure and the residue redissolved in about $10 \mathrm{ml}$. of $0.01 \mathrm{M}$-phosphate buffer, pH5.8. EDTA (disodium salt) $(5 \mu$ moles) was then added, followed by an excess of clostridial extract equivalent to 50 times the required amount. The mixture was incubated in a Dubnoff shaker for $5 \mathrm{~min}$. at $37^{\circ}$, and diluted with 20 times its volume of water. Free bile acids released were recovered by extracting the solution three times with equal volumes of ether after acidification to $\mathrm{pH} 1$ with $6 \mathrm{~N}-\mathrm{HCl}$.

Table 2. Recovery of added free bile acids from ratliver homogenate

Free bile acid $(40 \mu \mathrm{g}$.) was added to $20.0 \mathrm{ml}$. of $10 \%$ rat-liver homogenate and extracted as usual. A control was processed without added bile acids to determine the amount of endogenous bile acids.

$\begin{array}{lcc}\text { Bile acid } & \begin{array}{c}\text { recovered } \\ (\mu \mathrm{g} .)\end{array} & \begin{array}{c}\text { Recovery } \\ (\%)\end{array} \\ \text { recholic acid } & \mathbf{3 6 \cdot 8} & \mathbf{9 2 \cdot 0} \\ \text { mycholic acid } & \mathbf{3 3 . 5} & \mathbf{8 3 \cdot 8} \\ \text { nodeoxycholic acid } & \mathbf{3 2 \cdot 9} & \mathbf{8 2 \cdot 3} \\ \text { odeoxycholic acid } & \mathbf{3 3 \cdot 5} & \mathbf{8 3 \cdot 8} \\ \text { lic acid } & \mathbf{3 2 \cdot 7} & \mathbf{8 1 \cdot 8}\end{array}$

\section{Table 1. Recovery of added glycocholic acid and taurocholic acid from rat-liver homogenates}

After extraction from a $10 \%$ homogenate, the conjugates were cleaved by the classical alkaline hydrolysis procedure.

$\begin{array}{ccccc}\text { Bile acid } & \begin{array}{c}\text { Vol. of } \\ \text { homogenate }\end{array} & \begin{array}{c}\text { Bile acid } \\ \text { added } \\ (\mu \mathrm{g} .)\end{array} & \begin{array}{c}\text { Bile acid* } \\ \text { recovered } \\ (\mu \mathrm{g} .)\end{array} & \begin{array}{c}\text { Recovery } \\ (\%)\end{array} \\ \text { Taurocholic acid } & (\mathrm{ml}) & 200 & 160 & 80 \cdot 0 \\ & 5 \cdot 0 & 500 & 395 & \mathbf{7 9 \cdot 0} \\ \text { Glycocholic acid } & 10 \cdot 0 & 500 & 424 & \mathbf{8 4} \cdot 8 \\ & 10 \cdot 0 & 200 & 157 & 78 \cdot 5 \\ & 10 \cdot 0 & 200 & 154 & 77 \cdot 0\end{array}$

* Determined as free bile acids and calculated as conjugated bile acids. A control was processed in each case to determine the amount of endogenous bile acids. Table 3. Comparison of recoveries from chemical and enzymic hydrolysis of added bile acid
conjugates

Bile acids were added to a purified (Amberlyst-column) extract of bile acids from rat liver. Values are the means of several replicate analyses. A control was processed in each case to determine the amount of endogenous bile acids. The enzyme control did not contribute any peaks on gas-liquid chromatography.

\begin{tabular}{|c|c|c|c|c|c|c|c|c|}
\hline \multirow[b]{3}{*}{ Bile acid } & \multicolumn{4}{|c|}{ Chemical hydrolysis } & \multicolumn{4}{|c|}{ Enzymic hydrolysis } \\
\hline & \multirow{2}{*}{$\begin{array}{c}\text { Bile acid } \\
\text { added } \\
(\mu \mathrm{g} .)\end{array}$} & \multicolumn{2}{|c|}{$\begin{array}{l}\text { Cholic acid in } \\
\text { standard ( } \mu \mathrm{g} .)\end{array}$} & \multirow{2}{*}{$\begin{array}{c}\text { Recovery } \\
(\%)\end{array}$} & \multirow{2}{*}{$\begin{array}{l}\text { Bile acid } \\
\text { added } \\
(\mu \mathrm{g} .)\end{array}$} & \multicolumn{2}{|c|}{$\begin{array}{l}\text { Cholic acid in } \\
\text { standard ( } \mu \mathrm{g} .)\end{array}$} & \multirow{2}{*}{$\begin{array}{c}\text { Recovery } \\
(\%)\end{array}$} \\
\hline & & Calc. & Found & & & Calc. & Found & \\
\hline Glycocholic acid & 200 & $175 \cdot 6$ & $140 \cdot 8$ & $80 \cdot 2$ & 100 & $87 \cdot 8$ & $78 \cdot 7$ & $89 \cdot 6$ \\
\hline Taurocholic acid & 500 & $396 \cdot 0$ & $\mathbf{3 4 7 \cdot 7}$ & $87 \cdot 8$ & 100 & $79 \cdot 2$ & $68 \cdot 9$ & $87 \cdot 0$ \\
\hline
\end{tabular}


Alumina chromatography. Since we had not previously studied the isolation of lithocholic acid in detail, we reexamined this aspect and obtained quantitative recoveries by modifying the alumina chromatographic procedure. Bile acid methyl esters were transferred to the alumina column with about $10 \mathrm{ml}$. of benzene-hexane $(1: 9, \mathrm{v} / \mathrm{v})$ and washed with about $40 \mathrm{ml}$. of the same solvent mixture. Lithocholic acid methyl ester was eluted with $70 \mathrm{ml}$. of benzene and all the other bile acid methyl esters with $40 \mathrm{ml}$. of methanol-acetone $(1: 9, \mathrm{v} / \mathrm{v})$.

\section{RESULTS}

The isolation of both free and conjugated bile acids from tissue homogenates is represented in Scheme 1. Of several solvents examined, $95 \%(\mathrm{v} / \mathrm{v})$ ethanol containing $0.1 \%(v / v)$ of aq. ammonia (sp.gr. $0 \cdot 88$ ) gave the best results. Since all other stages of purification and determination except enzymic hydrolysis of conjugates and alumina chromatography are essentially the same as those used in the gas-liquid chromatography of serum bile acids (Sandberg et al. 1965), we examined only the overall efficiency of the procedure.

The overall recovery of glycocholic acid and taurocholic acid added to a $10 \%$ homogenate of rat liver is presented in Table 1 , where the conjugates were cleaved by alkaline hydrolysis. The recovery of unconjugated bile acids added to ratliver homogenates shown in Table 2 consistently yielded over $80 \%$. A comparison of the chemical and enzymic hydrolytic procedures was made to determine the relative merits of the two techniques (Table 3). The recovery of added glycocholic acid by enzymic cleavage was higher than that by chemical hydrolysis. There was no difference in the recovery of taurocholic acid by the two methods. Several homogenates of rat liver were extracted and the conjugates were subjected to both methods of cleavage. In each enzymic procedure, a control without any biological extract was maintained to exclude the possibility of interfering peaks contributed by the enzyme (Fig. 1). Within the range $0 \cdot 2-1 \cdot 0 \mu \mathrm{g}$. a linear relationship exists between peak areas and amounts of trifluoroacetyl bile acid methyl esters injected into the column (Fig. 2).

In previous studies (Sandberg et al. 1965) a column with FS-1265 alone as the stationary phase was used. Since this column lacked reproducibility as well as consistency in response, we developed a highly reproducible triple-component column (FS1265-SE 30-NGS). Standard relative retention times for the trifluoroacetyl methyl esters for a series of 20 different substituted cholanic acids have been described (Okishio \& Nair, 1966a). In the present study additional data are presented to characterize this column. Bile acid methyl esters were converted into their corresponding trimethylsilyl ethers before gas-liquid chromatography, and
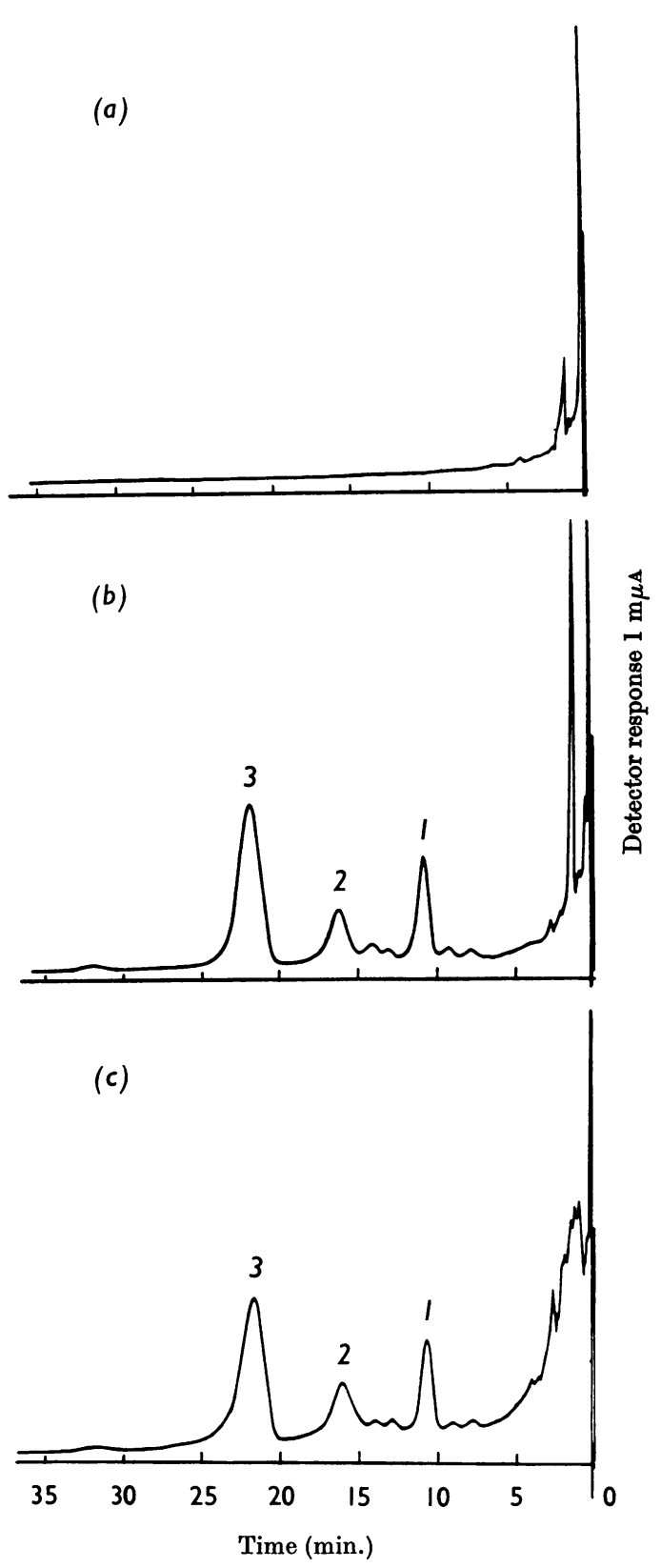

Fig. 1. Gas-liquid chromatography of rat-liver bile acids in the form of methyl ester trifluoroacetates: comparison of enzymic and chemical hydrolytic procedures for conjugated bile acids. (a) Enzyme control with no extract of rat-liver homogenate; (b) enzymic cleavage; (c) alkaline hydrolysis in autoclave. 1 , Deoxycholic acid; 2 , hyodeoxycholic acid; 3 , cholic acid. The conditions employed for gas-liquid chromatography were as described in the Experimental section. 
retention times were determined relative to methyl deoxycholate (Table 4).

\section{DISCUSSION}

Of several types of biological material, bile, blood and faeces are the most widely studied for their bile acid composition (Sjövall, 1964a). In contrast, our knowledge of bile acids and their function at the cellular and subcellular levels has remained unexplored, largely because of the lack of suitable

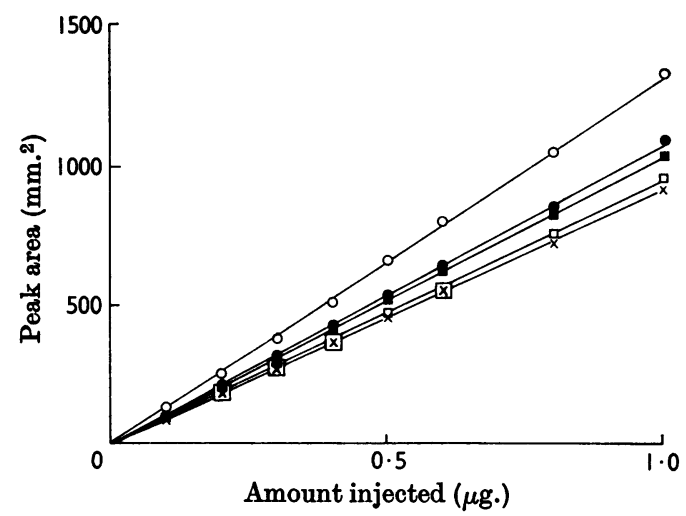

Fig. 2. Linear relationship between amounts of trifluoroacetylated methyl esters of bile acids and peak areas obtained from gas-liquid chromatography. $O$, Lithocholic acid;, , deoxycholic acid; $\square$, chenodeoxycholic acid; $\square$, hyodeoxycholic acid; $x$, cholic acid. methods of isolation and determination. The extraction of the substituted cholanic acids (bile acids) from cells (animal and bacterial) presents special problems since they are relatively more polar than other sterols and are often firmly bound to protein in the particulate material (Gustafsson \& Norman, 1962).

To extract bile acids from faeces quantitatively, several solvent systems have been proposed, e.g. hot ethanol, chloroform-methanol $(1: 1, v / v)$ and methylal-methanol (4:1, v/v) (Sjövall, 1964a; Antonis \& Bersohn, 1962). Our method for the extraction of bile acids from tissue homogenates is essentially an adaptation of the hot-ethanol system, except for the added ammonia, which assists in dissociation of protein-bound bile acids without cleavage of the conjugated forms. Preliminary purification on Amberlyst A-26 anion-exchange resin, as described by Sandberg et al. (1965), gave both free and conjugated bile acids.

The hydrolytic cleavage of bile acid conjugates presents a difficult problem in the analytical methodology of bile acids. Since alkaline hydrolysis usually results in some loss of bile acids, a new enzymic procedure has been developed. Cell-free extracts from Clostridium perfringens (A.T.C.C. 19574 ) rapidly cleave the naturally occurring conjugates of the bile acids under milder conditions than those employed for their chemical hydrolysis (Nair et al. 1965). Tissue extracts subjected to this hydrolytic procedure inhibit the enzyme (peptidebond hydrolase) to a small extent, but this could be partially prevented by the addition of a small

\section{Table 4. Gas-liquid chromatography of trimethylsilyl ether derivatives of substituted methyl} cholanates on FS-1265 and FS-1265-SE 30-NGS columns

Results are given for the compounds with free hydroxyl groups (OH) and for the trimethysily] ethers (TMSi). Values in parentheses were obtained at a column temperature of $220^{\circ}$ (methyl deoxycholate retention time $23 \mathrm{~min}$.). The outlet flow rate was $75 \mathrm{ml} . / \mathrm{min}$.

Retention time relative to that of methyl deoxycholate

\begin{tabular}{|c|c|c|c|c|}
\hline \multicolumn{2}{|c|}{ Stationary phase ...... } & FS-1265* & \multicolumn{2}{|c|}{ FS-1265-SE 30-NGS } \\
\hline methyl cholanate & OH & TMSi & $\mathrm{OH}$ & TMSi \\
\hline $\begin{array}{l}3 \alpha \text {-Hydroxy } \\
3 \alpha, 12 \alpha \text {-Dihydroxy } \\
3 \alpha, 7 \alpha \text {-Dihydroxy } \\
3 \alpha, 7 \beta \text {-Dihydroxy } \\
3 \alpha, 6 \alpha \text {-Dihydroxy } \\
3 \alpha, 6 \beta \text {-Dihydroxy } \\
3 \alpha, 7 \alpha, 12 \alpha-\text { Trihydroxy } \\
3 \alpha, 6 \alpha, 7 \alpha-\text { Trihydroxy } \\
3 \alpha, 6 \alpha, 7 \beta \text {-Trihydroxy }\end{array}$ & $\begin{array}{l}0 \cdot 50 \\
1 \cdot 00 \dagger \\
1 \cdot 13 \\
1 \cdot 25 \\
1 \cdot 48 \\
1 \cdot 19 \\
2 \cdot 34 \\
2 \cdot 63 \\
2 \cdot 40\end{array}$ & $\begin{array}{c}0 \cdot 30 \\
0 \cdot 32,0 \cdot 60 \\
0 \cdot 35,0 \cdot 80 \\
0 \cdot 34,0 \cdot 62 \\
0 \cdot 36 \\
0 \cdot 35 \\
0 \cdot 36,0 \cdot 60,1 \cdot 25 \\
0 \cdot 45,0 \cdot 61 \\
0 \cdot 67\end{array}$ & $\begin{array}{l}0 \cdot 34 \\
1 \cdot 00 \ddagger \\
1 \cdot 10 \\
1 \cdot 23 \\
1 \cdot 58 \\
1 \cdot 28 \\
(3 \cdot 31) \\
(3 \cdot 86) \\
(3 \cdot 34)\end{array}$ & $\begin{array}{c}0.20 \\
0 \cdot 22,0.45 \\
0.22,0.50 \\
0.28,0.54 \\
0 \cdot 26 \\
0 \cdot 24,0.56 \\
0.23,0 \cdot 47,1.34 \\
0.31,0.47 \\
0.51\end{array}$ \\
\hline
\end{tabular}

* $1.2 \mathrm{~g}$. dissolved in $150 \mathrm{ml}$. of acetone for $15 \mathrm{~g}$. of support.

$\uparrow$ Methyl deoxycholate retention time $22 \mathrm{~min}$. at column temperature of $210^{\circ}$.

$\ddagger$ Methyl deoxycholate retention time $36 \mathrm{~min}$. at column temperature of $210^{\circ}$. 
amount of EDTA (disodium salt). Whereas enzymic hydrolysis gave a higher recovery for glycocholic acid (Table 3), no difference was noticed with taurocholic acid. This is probably attributable to the lower rate at which the latter is cleaved (Nair et al. 1965). The enzyme itself does not contribute any peaks to the final gas-liquid chromatography (Fig. 1) and has the added advantages of rapidity and lower temperature for hydrolysis.

The bile acids are usually converted into their methyl ester trifluoroacetates and chromatographed on two types of columns, one with FS-1265 as the only liquid phase and the other a mixture of phases consisting of FS-1265-SE 30-NGS. Identification of peaks is possible from standard relative retention data (Sjövall, 1964a; Okishio \& Nair, 1966a). Under the specified reaction conditions, substituted cholanic acids are known to provide the methyl esters and trifluoroacetates quantitatively. In contrast, not all of the trimethylsilyl ether derivatives of bile acid methyl esters are readily formed; the axial hydroxyl groups are less readily converted into the silyl ethers than the corresponding equatorial hydroxyl groups (Sjövall, 1964b; Briggs \& Lipsky, 1965) (Table 4). The product obtained on conversion of all hydroxyl groups of a substituted cholanic acid usually exhibits the shortest retention time compared with that of a partially converted one. No attempt has been made to identify the secondary peaks.

Another unique feature in this study is the introduction of a new silyl donor, bis(trimethylsilyl)acetamide, for the preparation of trimethylsilyl ether derivatives. This method has advantages over the classical method utilizing hexamethyldisilazane in that the reagent itself could serve as a solvent and that there are no precipitates, which require elimination. Bis(trimethylsilyl)acetamide readily transfers one of its silyl groups, forming the more stable monotrimethylsilylacetamide (J. F. Klebe, personal communication). This reagent has been successfully used for the preparation of trimethylsilyl ether derivatives of vitamin $\mathrm{D}$ and the substituted tocols (Nair \& deLeon, 1966; Nair, Sarlos \& Machiz, 1966).

This work was supported by Grants AM-01417 and AM-02131 from the U.S. Public Health Service, National Institutes of Health, General Research Support Grant 5SO-1FR-05478-04 and Training Grant HE-5399 from the National Heart Institute. T.O. was a trainee of the National Heart Institute.

\section{REFERENCES}

Antonis, A. \& Bersohn, I. (1962). Amer. J. clin. Nutr. 11, 142.

Briggs, T. \& Lipsky, S. R. (1965). Biochim. biophys. Acta, 97, 579.

Gustafsson, B. E. \& Norman, A. (1962). Proc. soc. exp. Biol., N.Y., 110, 387.

Haslewood, G. A. D. (1964). Biol. Rev. 39, 540.

Irwin, J. L., Johnston, C. G. \& Kopala, J. (1944). J. biol. Chem. 153, 439.

Levin, S. J., Irwin, J. L. \& Johnston, C. G. (1961). Analyt. Chem. 33, 856.

Nair, P. P. \& deLeon, S. (1966). In Progress in Biochemical Pharmacology, vol. 2. Ed. by Paoletti, R. Basle: S. Karger A.-G. (in the Press).

Nair, P. P., Gordon, M., Gordon, S., Reback, J. \& Mendeloff, A. I. (1965). Life Sci., 4, 1887.

Nair, P. P., Sarlos, I. \& Machiz, J. (1966). Arch. Biochem. Biophys. 114, 488.

Norman, A. (1955). Ark. Kemi, 8, 331.

Okishio, T. \& Nair, P. P. (1965). Fed. Proc. 24, 564.

Okishio, T. \& Nair, P. P. (1966a). Analyt. Biochem. 15, 360.

Okishio, T. \& Nair, P. P. (1966b). Biochemistry, 5, 3662.

Sandberg, D. H., Sjövall, J., Sjövall, K. \& Turner, D. A. (1965). J. Lipid Res. 6, 182.

Schlenk, H. \& Gellerman, J. L. (1960). Analyt. Chem. 80, 1412.

Sjövall, J. (1964a). Meth. biochem. Anal. 12, 118.

Sjövall, J. (1964b). In New Biochemical Separations, p. 65. Ed. by James, A. T. \& Morris, L. J. London: D. Van Nostrand Co. Ltd. 